\title{
Fibras de carbono a partir de lignina: uma revisão da literatura
}

\author{
Carbon fiber from lignin: a literature review
}

\author{
Felipe Souto $^{1}$, Veronica Calado ${ }^{1}$, \\ Nei Pereira Junior ${ }^{2}$
}

\footnotetext{
${ }^{1}$ Laboratório de Termoanálises e Reologia - LABTeR - NBPD/LADEQ/UFRJ CEP: 21941 - 21941-972, Rio de Janeiro, RJ.

e-mail: fsouto@eq.ufrj.br; calado@eq.ufrj.br

${ }^{2}$ Laboratório de Desenvolvimento de Bioprocessos - LADEBIO - NBPD/LADEQ/UFRJ CEP: 21941-972, Rio de Janeiro, RJ.

e-mail: nei@eq.ufrj.br
}

\section{RESUMO}

Os precursores mais empregados para obtenção da fibra de carbono são a poliacrilonitrila, o piche e o rayon. Com o aumento da demanda de materiais compósitos leves e de alta resistência, a produção da fibra de carbono tem aumentado exponencialmente e novos precursores têm sido requisitados. A lignina, um material orgânico natural, tem sido estudada como possível candidata para a produção das fibras. Além de ser rejeito industrial e de biorrefinarias, as fibras de carbono obtidas com a lignina podem ter um custo mais vantajoso quando comparado com os demais precursores comerciais. Em decorrência da biodiversidade de vegetais na natureza, a lignina pode apresentar diferentes estruturas. O método de recuperação também é parâmetro que influencia diretamente na sua composição. Como as propriedades térmicas para extrusão são fortemente dependentes dessas e de muitas outras variáveis, muitas pesquisas têm sido reportadas utilizando lignina pura de diversas fontes, lignina modificada e com adição de plastificantes. As etapas de pré-tratamento, termoestabilização e carbonização/grafitização também têm sido avaliadas para conferir melhores propriedades mecânicas ao produto final. Não obstante serem muitas as condições para a produção da fibra de carbono a partir da lignina, resultados bastante promissores têm sido alcançados. As aplicações em diversas áreas estão diretamente relacionadas com o conjunto de propriedades mecânicas inerentes a ela. A fibra de carbono proveniente da lignina vem contribuir com inúmeros empregos no mercado, de maneira a baratear sua produção, minimizar a dependência de materiais fósseis e tornar sua manufatura ecologicamente sustentável.

Palavras-chave: lignina, fibra de carbono, fibra verde

\section{ABSTRACT}

The most applied precursors to obtain carbon fiber are polyacrylonitrile, pitch and rayon. With the increased demand of lightweight composites and high strength, carbon fiber manufacting has increased exponentially and new precursors are been request. Lignin, a natural organic material, has been studied as possible candidate. Besides being an industrial and biorrefinary waste, lignin-based carbon fibers have a lower cost compared to other commercial precursors. Because of the biodiversity of plants in nature, lignin can present different structures. The lignin extraction method can directly influence the composition. As thermic extrusion properties are hardly dependent on this and other properties, many researches have been reported using pure lignin from different sources, modified lignin and plasticizers addiction. Steps of pretreatment, thermostabilization and carbonization/graphitization have also been evaluated to give better mechanical properties to the final product. Nevertheless many conditions required to manufacture lignin-based carbon fiber, promising results have been achieved. The set of mechanical properties inherent to the fiber allows its application to different areas. Lignin-based carbon comes to collaborate on cheapening its production, minimizing the dependence of fossil materials and making its manufacture process ecologically sustainable.

Keywords: lignin, carbon fiber, green fiber. 


\section{INTRODUÇÃO}

A fibra de carbono é descrita na Textile Terms and Definition como contendo pelo menos $90 \%$ de carbono no seu processamento pirolítico, sendo que a fibra grafitizada atinge $99 \%$ de carbono, na sua estrutura [1]. O diâmetro de seus filamentos mede, em regra, de 5 a $15 \mu \mathrm{m}$ [2]. É um material de engenharia de grande aplicação e tem sido utilizado como reforço na matriz polimérica de materiais compósitos devido ao seu alto módulo e força específica (razão entre a resistência a tração e a gravidade específica de um material) []] . É leve, flexível, resistente à fadiga e ao calor, praticamente inerte, isola radiações eletromagnéticas, possui baixa expansão térmica, além de alta resistência mecânica $[\underline{4}, \underline{5}, \underline{6}]$. Comparativamente, é dez vezes mais forte e cinco vezes mais leve que o aço [7]. Tais propriedades são decorrentes da orientação dos átomos de carbono ao longo do eixo da fibra.

Os compósitos reforçados com fibra de carbono têm ampla aplicação na fabricação de materiais esportivos, de construção civil, produtos de pesca, indústria automotiva, fuselagem de aviões, próteses, equipamentos radiológicos, maquinaria têxtil, instrumentos musicais, entre outros (Tabela 1). Nas últimas décadas, sua demanda tem aumentado consideravelmente em decorrência de suas propriedades mecânicas. Segundo a Zoltek, conhecida companhia de manufatura, desenvolvimento e venda comercial de fibras de carbono, estima-se uma demanda de mercado de cerca de 800 milhões de libras para 2017 []]. Um exemplo é a indústria automobilística, em que as exigências ambientais têm requerido automóveis menos poluentes e consequentemente mais leves, sendo os materiais compósitos reforçados com fibras de carbono, uma excelente solução [9]. Veículos 10\% mais leves implicam uma economia de 6-8\% quilômetros/galão []].

Tabela 1: Algumas propriedades físicas e aplicações da fibra de carbono

\begin{tabular}{|c|c|}
\hline Propriedades Físicas & Aplicação \\
\hline Força, resistência específica, peso leve & $\begin{array}{l}\text { Aeronáutica: asas, superfícies de controle; } \\
\quad \text { automotivo: molas, cabos de pneus; } \\
\text { artigos esportivos: esquis, raquetes de tênis }\end{array}$ \\
\hline $\begin{array}{l}\text { Elevada estabilidade dimensional, baixo } \\
\text { coeficiente de expansão térmica, e bai- } \\
\text { xa abrasão }\end{array}$ & $\begin{array}{l}\text { Mísseis, freios de aeronaves, aeroespacial antena e estruturas de apoio, } \\
\text { telescópios grandes, bancos ópticos, guias de onda para estável de alta } \\
\text { frequência }(\mathrm{GHz}) \text { quadros de medição de precisão }\end{array}$ \\
\hline $\begin{array}{l}\text { Bom amortecimento de vibrações, força } \\
\text { e tenacidade }\end{array}$ & $\begin{array}{l}\text { Equipamentos de áudio, alto-falantes, bobinas, braços de coleta, instru- } \\
\text { mentos musicais, braços robóticos }\end{array}$ \\
\hline Condutividade elétrica & $\begin{array}{c}\text { Capuzes de automóveis, carcaças e bases para equipamentos eletrônicos, } \\
\text { pincéis, papéis e plásticos condutores, eletrodos, elementos de aqueci- } \\
\text { mento, cabos supercondutores }\end{array}$ \\
\hline Filtros biológicos & $\begin{array}{l}\text { Filtros de sangue, dispositivos protéticos, cirúrgicos e equipamentos de } \\
\text { raios } \mathrm{X} \text {, implantes, tendão/ligamento reparação }\end{array}$ \\
\hline $\begin{array}{l}\text { Resistência à fadiga, autolubrificação, } \\
\text { alto amortecimento }\end{array}$ & $\begin{array}{l}\text { Máquinas têxteis, engenharia geral, os rolamentos de alta tensão, os vo- } \\
\text { lantes }\end{array}$ \\
\hline Inércia química, resistência à corrosão & $\begin{array}{l}\text { Indústria química; campo nuclear; válvulas, selos, juntas e componentes } \\
\text { de bombas em plantas de processos }\end{array}$ \\
\hline Propriedades eletromagnéticas & Anéis geradores de contenção grandes, equipamentos radiológicos \\
\hline
\end{tabular}

Fonte: [10].

No entanto, a manufatura das fibras ainda é muito onerosa tornando as pesquisas por precursores mais viáveis e com boas propriedades mecânicas, alvo de interesse. É possível destacar três principais materiais orgânicos como fontes de obtenção da fibra: piche (mesofásico e isotrópico), rayon e poliacrilonitrila (PAN). Desses, o precursor mais importante para aplicações estruturais devido ao seu alto percentual de carbono e que vem sendo largamente utilizado em produção comercial, é a PAN. Seus inconvenientes são o custo do precursor (cerca de $50 \%$ do custo da fibra de carbono), o rendimento, a toxicidade do solvente e a grafitização lenta $[\underline{11}, \underline{12}, \underline{13}]$. Como substitutos mais viáveis economicamente, alguns subprodutos e produtos residuais naturais ou sintéticos têm sido estudados. Para tanto, é fundamental que essa nova matéria-prima seja um produto orgânico com elevado teor de carbono, que o material final forneça pelo menos $10 \%$ em massa em relação ao seu precursor e que não passe para o estado líquido ou pegajoso durante a etapa de carbonização [14]. Assim, a dificuldade básica é combinar vários pontos, tais como a viabilidade econômica do precursor, o rendimento, os custos de processamento, entre outros [15].

A possibilidade em usar derivados de biomassa como matéria-prima para obtenção da fibra de carbono aumenta a disponibilidade de novos precursores, diminui sensivelmente o custo de produção e diminui o impacto ambiental associado à produção da fibra [16].

A lignina é um material termoplástico, componente de recursos renováveis, com grande potencial para produção da fibra de carbono. É uma macromolécula fenólica, com estrutura complexa, heterogênea, tridimensi- 
onal, com alto teor de carbono, presente em todos os vegetais e ocupa a posição de segunda macromolécula orgânica mais abundante da natureza [ㅍ,ㄱ].

As indústrias de papel e celulose geram, durante o seu processo, toneladas de lignina como subproduto. Entretanto, sua utilização comercial está limitada a menos de $2 \%$ de sua produção $[\underline{5}, 18]$. Isso porque atualmente, a lignina contida no licor negro gerado nessas indústrias tem sido aplicada fundamentalmente na queima para aproveitamento energético na própria planta industrial. A lignina é um material de baixo custo, sustentável, com disponibilidade futura em biorrefinarias - subproduto da produção de etanol de $2^{\mathrm{a}}$ geração.

O conceito de biorrefinaria está intrinsecamente associado à utilização de derivados de biomassa, tais como materiais lignocelulósicos, para aproveitamento energético, combustíveis para transporte e matriz para construção de uma diversidade de substâncias químicas. Como as novas tendências tecnológicas convergem para fontes de energia e matérias-primas renováveis tendo em voga, alternativas menos poluentes e minimizando a dependência de fontes fósseis, esses complexos de refino de biomassa têm ganhado importante destaque no cenário global. Sua maior atenção está concentrada na valorização da celulose e hemicelulose, denominados de plataformas de açúcares básicos [19]. A lignina é considerada como um subproduto de baixo valor agregado, com estrutura complexa e reatividade incerta, sendo esses os fatores limitantes para seu uso em larga escala nas biorrefinarias [19]. A conversão da lignina em um produto como a fibra de carbono é um caminho para potencializar o seu aproveitamento.

Esse artigo tem como objetivo fazer uma breve revisão da literatura acerca da lignina como precursor para obtenção da fibra de carbono.

\section{BREVE HISTÓRICO}

A fibra de carbono foi produzida pela primeira vez em torno de 1880 por Thomas Edison que carbonizou bambu para produzir filamento para lâmpadas elétricas. Mais tarde, o tungstênio acabou por substituir a fibra de carbono no intento [20]. Apenas por volta de 1950, quando a busca por materiais ablativos para foguetes iniciou, é que as fibras de carbono para aplicação em reforços compósitos ganharam interesse comercial [20,21]. Em 1958, Roger Bacon produziu fibras de carbono à base de rayon, na Union Carbide Parma Technical Center. Por volta de 1960, Shindo utilizou PAN, obtendo fibras carbonizadas e grafitizadas com resistência à tração e módulo de Young de $750 \mathrm{MPa}$ e $112 \mathrm{GPa}$, respectivamente. A atividade cresceu muito nas décadas de 60 e 70, estimulando a busca por precursores que fornecessem rendimento de qualidade na obtenção da fibra [20].

Na década de 70, acreditava-se que a matéria-prima de menor preço e que produzisse melhor rendimento na etapa de carbonização final seria o precursor dominante. No entanto, para a surpresa geral, a poliacrilonitrila seguiu sendo a pioneira no mercado, devido às melhores propriedades conferidas ao material final, bem como ao seu rendimento em carbono. O rayon assumiu a posição de terceiro lugar, embora seja um produto mais barato. Isso se justifica pelo fato de fornecer uma fibra de propriedades inferiores e baixo rendimento após a etapa de carbonização. É possível melhorar essas propriedades, tracionando as fibras durante a etapa de grafitização; porém, o custo da operação torna o processo desinteressante. Até o momento, a PAN continua ocupando a primeira posição de matéria-prima de obtenção da fibra de carbono [20,21].

A fibra de carbono utilizando lignina como precursor foi comercializada e desenvolvida pela primeira vez pela Nippon Kayaku Co. em escala piloto. O processo foi cessado mediante a obtenção de um produto com propriedades mecânicas pobres, resultado de uma lignina com muitas impurezas $[11, \underline{10}]$. Na década de 70, um processo semelhante foi patenteado por Mannsmann e colaboradores, usando uma solução aquosa de lignina ou sais de lignina, com adição de polímero plastificante, como o óxido de polietileno (PEO) [14].

\section{CLASSIFICAÇÃO E TIPOS}

As fibras de carbono podem ser classificadas de acordo com o seu módulo, força, precursores e temperatura de tratamento térmico. A Tabela 2 apresenta algumas dessas classificações de maneira resumida.

De acordo com as propriedades da fibra, suas aplicações são diversas. A Figura 1 apresenta a relação entre módulo, resistência à tração e aplicabilidade para usos comuns das fibras.

\section{MANUFATURA DA FIBRA DE CARBONO}

O processo de obtenção da fibra de carbono, dependendo da metodologia empregada, é composto por algumas etapas até adquirir as propriedades inerentes ao produto final. Em se tratando de precursores poliméricos, como no caso da lignina, três etapas básicas são comuns: fiação, termoestabilização e carbonização. 
Tabela 2: Classificação e tipos de fibra de carbono

\begin{tabular}{|c|c|c|}
\hline \multirow{6}{*}{ 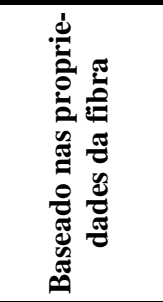 } & TIPOS & VALORES \\
\hline & Módulo ultra-alto & $>450 \mathrm{GPa}$ \\
\hline & Módulo alto & $350-450 \mathrm{GPa}$ \\
\hline & Módulo intermediário & $200-350 \mathrm{GPa}$ \\
\hline & Baixo módulo e alta tensão & $\begin{array}{c}\text { módulo < } 100 \mathrm{GPa} / \text { resistência a tensão }>3 \\
\mathrm{GPa}\end{array}$ \\
\hline & Super alta tensão & resistência a tensão $>4,5 \mathrm{GPa}$ \\
\hline \multirow{5}{*}{ 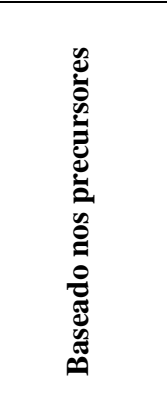 } & TIPOS & SUBTIPOS \\
\hline & Fibra de PAN & \\
\hline & Fibra de piche & mesofásico / isotrópico \\
\hline & Fibras de rayon & \\
\hline & Fibras com crescimento em fase vapor & \\
\hline \multirow{4}{*}{ 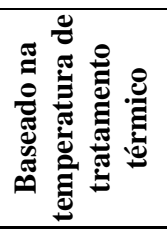 } & TIPOS & Temperatura/classificação \\
\hline & Tratamento de alto aquecimento & $>2000^{\circ} \mathrm{C} /$ alto módulo \\
\hline & Tratamento de aquecimento intermediário & em torno de $1500^{\circ} \mathrm{C} /$ alta força \\
\hline & Tratamento de baixo aquecimento & $\begin{array}{c}\text { em torno de } 1000^{\circ} \mathrm{C} / \text { baixo módulo e baixa } \\
\text { força }\end{array}$ \\
\hline
\end{tabular}

Fonte: [1].

A etapa de grafitização é uma etapa complementar à carbonização, onde a temperatura de tratamento térmico a ser empregada é elevada a valores em torno de $3000^{\circ} \mathrm{C}$.

Um método que difere dos precursores poliméricos não apenas na síntese, mas também na sua microestrutura e propriedades, é o de deposição química em fase vapor. Envolve apenas uma única etapa, necessitando para tanto, um catalisador particulado metálico ultrafino disperso em substrato cerâmico [22]. O método utiliza alguns tipos de hidrocarbonetos gasosos (como metano, benzeno) diluídos com outros gases (como $\mathrm{H}_{2}, \mathrm{CO}, \mathrm{CO}_{2}$ ), com temperaturas acima de $1000{ }^{\circ} \mathrm{C}$. Ocorre uma decomposição do hidrocarboneto na partícula catalítica, levando à absorção de carbono da mesma e saída contínua de uma estrutura tubular bem organizada. Embora esse método não se aplique à lignina, foco deste trabalho, ele é um possível processo de manufatura da fibra de carbono, sendo estudado por diversos pesquisadores $[22,23,24,25,26, \underline{27}, \underline{28}, \underline{29}, \underline{30}]$.

Uma vez tendo-se a fibra, é conveniente proceder um tratamento superficial na mesma antes de usá-la na fabricação de materiais compósitos.

Figura 1: Classificação por características mecânicas

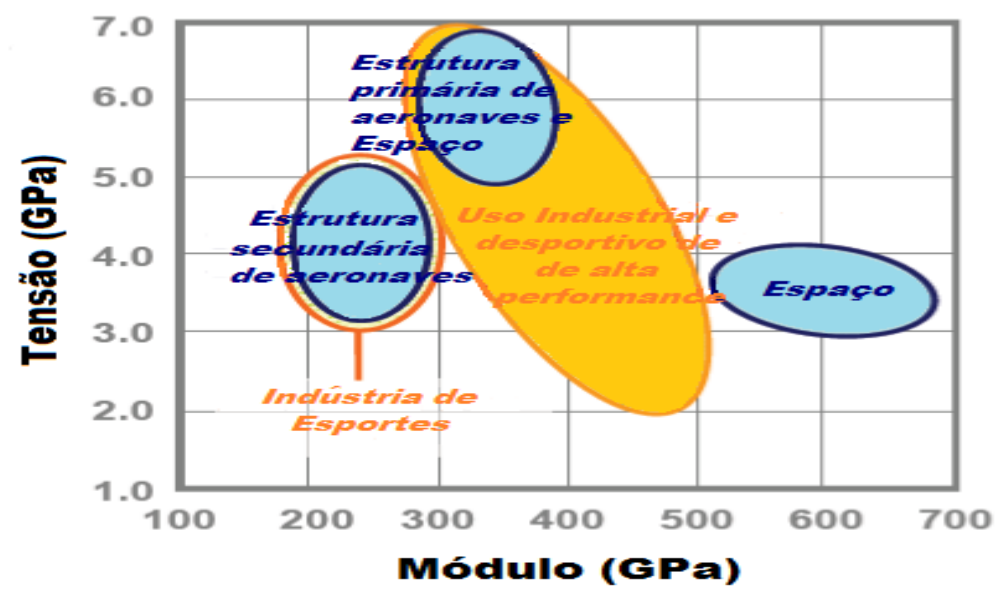

Fonte: [31]. 


\subsection{Fiação ou Extrusão da Fibra}

A fiação de uma massa para obtenção de fibras pode ser efetuada de três formas distintas: fiação por fusão, fiação úmida e fiação seca. Na primeira, o precursor é fundido e extrudado por orifícios; à medida que emergem, os filamentos resfriam e solidificam no formato adequado. É o processo preferido, uma vez que não faz uso de nenhum outro recurso, que não o da fusão da matéria- prima. No segundo caso, uma solução concentrada do precursor é extrudada pelos orifícios, em um banho de coagulação. O solvente é mais solúvel no fluido de coagulação do que o precursor; logo, à medida que a solução emerge dos orifícios, o precursor precipita na forma da fibra. O último processo também fia uma solução concentrada do precursor. A diferença é que o fio é extrudado dentro de uma câmara de secagem onde o solvente evapora e o precursor precipita na forma da fibra. Caso a matéria-prima degrade na (ou próximo da) temperatura de fusão, é recomendado o uso da fiação a seco ou úmida [32].

A fibra de PAN, por exemplo, pode ser gerada hoje em dia, tanto por fiação seca, como por fiação úmida, muito embora a fiação úmida seja preferida [33]. Já as fibras geradas a partir da lignina e piche têm sido obtidas, geralmente, por fiação por fusão $[\underline{5}, \underline{16}]$.

\subsection{Termoestabilização da Fibra}

Geralmente, o material extrudado na etapa da fiação, precisa passar por um tratamento térmico para o aumento da sua temperatura de transição vítrea ("glass transition point" - $\mathrm{T}_{\mathrm{g}}$ ). Essa etapa é necessária para garantir uma infusibilidade ao material durante a etapa subsequente (carbonização), em que a lignina deixa de ser termoplástica e se torna termorrígida.

É uma das etapas mais caras do processo e estudos de otimização têm sido empregados de forma a minimizar o tempo da estabilização, embora garantindo que se alcancem as propriedades desejadas de estabilidade [34]. A qualidade da fibra fica comprometida caso a etapa de termoestabilização seja efetuada rapidamente [32]. É preciso que a taxa de aquecimento do processo seja lenta, de forma que a $\mathrm{T}_{\mathrm{g}}$ aumente mais rápido do que a temperatura da termoestabilização, oxidando os grupos funcionais [17]. Em alguns casos, submete-se uma tensão ao método para limitar a relaxação da estrutura polimérica durante o aquecimento [32].

No caso da lignina, como ela é composta de muitos átomos de oxigênio na sua cadeia, supõe-se que a etapa de termoestabilização seja eliminada devido às reações de auto-oxidação que ocorrem durante a carbonização. No entanto, os resultados experimentais têm demonstrado que essas reações não são o suficiente para aumentar a $\mathrm{T}_{\mathrm{g}}$ ao ponto de tornar a fibra infusível à etapa de carbonização carecendo, portanto, de promover a termoestabilização [18]. O processo geralmente é efetuado em atmosfera oxidante, onde é priorizado o ar como método simples e de baixo custo [34]. O tratamento consiste na introdução de ligações cruzadas oxigenadas entre as moléculas e incorporação de grupos oxidados, justificando o aumento da temperatura de transição vítrea [17]. Com o aumento da temperatura a baixas taxas de aquecimento, a $\mathrm{T}_{\mathrm{g}}$ aumenta mais rápido que a temperatura do sistema, mantendo o material em estado vítreo. Com altas taxas de aquecimento, as reações não conseguem manter a $\mathrm{T}_{\mathrm{g}}$ maior que a temperatura do sistema, fundindo o fio [17].

Há novas técnicas sendo estudadas visando a minimizar o tempo da oxidação e, consequentemente, minimizando custos na conversão. Trata-se do processo que combina o processo com plasma e o micro-ondas $[\underline{35}, \underline{36}]$.

A oxidação térmica da lignina é complexa e ainda não está bem caracterizada [17]. Enquanto nas fibras obtidas por piche mesofásico há variações de ganho e perda de massa, temperatura e tempo de exposição, na lignina há perda de massa decorrente da desidratação e condensação da mesma $[\underline{11}, \underline{34}, \underline{37}, \underline{38}]$. Nessa etapa, já ocorre um encolhimento e redução do diâmetro da fibra.

\subsection{Carbonização e Grafitização da Fibra}

A carbonização e a grafitização são estágios similares para materiais orgânicos, com a diferença do grau de orientação e cristalização alcançados de acordo com a temperatura.

A proposta de carbonizar a fibra é produzir folhas planas de grafenos turbostráticos (Figura 2), grafítica ou híbrida, com alto teor de carbono $[\underline{11}, \underline{34}]$. Essa etapa é promovida em atmosfera inerte e a maioria dos elementos não carbônicos da fibra é volatilizada na forma de metano, hidrogênio, cianeto, água, monóxido de carbono, dióxido de carbono, amônia e muitos outros gases, enriquecendo as ligações carbono-carbono e consequentemente melhorando as propriedades mecânicas, elétricas e térmicas da fibra. Precursores com alta quantidade de heteroátomos têm maior perda na carbonização devido à gaseificação, gerando consequentemente uma fibra com muitos poros e propriedades mecânicas baixas $[3 \underline{39}, \underline{40}, \underline{41}, \underline{5}, \underline{42}]$. A perda de massa nessa 
etapa varia com o precursor. No caso da PAN, está entre 55-60\% [32] e os piches isotrópicos variam de 20 $45 \%$, sempre com significativa contração dimensional [37].

A etapa de carbonização enriquece o percentual de carbono, enquanto a etapa de grafitização converte o carbono em grafite, que tem uma estrutura distinta [ [5].

A resistência máxima à tração é obtida a $1500^{\circ} \mathrm{C}$. Acima dessa temperatura, há aumento do módulo e redução da resistência. Uma taxa de carbonização rápida provoca defeitos estruturais à fibra, enquanto taxas lentas causam uma perda muito grande de heteroátomos. Recomenda-se uma otimização do processo [2].

Figura 2: Esquema estrutural de grafenos turbostráticos

Fonte: [ㅍ].

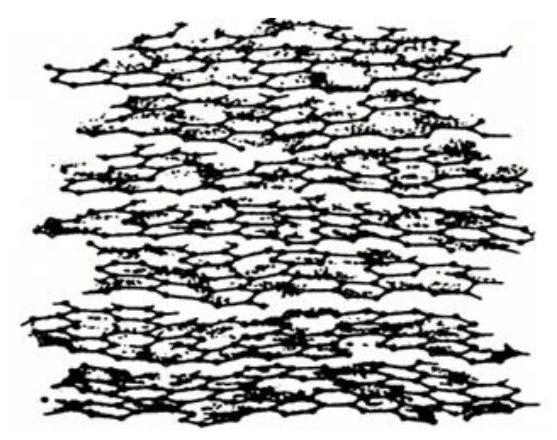

\subsection{Tratamento Superficial}

As fibras de carbono são usadas como reforço de materiais compósitos. No entanto, para que se obtenha um compósito de qualidade, é importante uma boa interação da fibra com a matriz polimérica. Uma das maneiras de se alcançar essa interação na interface matriz-fibra é promover um tratamento na superfície da mesma para melhorar as propriedades de adesão. Os tratamentos empregados consistem em uma limpeza e inclusão de grupos funcionais que podem ser por métodos oxidativos ou não-oxidativos. A maioria dos processos é feita por oxidação eletrolítica que anexa grupos carboxilas, carbonilas e hidroxilas na superfície de modo a favorecer a associação com a matriz [40]. Depois do tratamento, as fibras são cobertas com uma camada fina de resina, chamada sizing. Esse tratamento facilita o manuseio da fibra e melhora suas propriedades mecânicas [40].

\section{A LIGNINA COMO PRECURSOR}

\subsection{A lignina}

A lignina é um polímero natural aromático complexo, responsável por cerca de $30 \%$ dos carbonos da bioesfera [44]. Tem sua origem na desidrogenação dos álcoois cumarílico (unidade p-hidroxifenila), coniferílico (unidade guaiacil) e sinapílico (unidade siringil). Uma estrutura hipotética e suas unidades encontram-se representadas na Figura 3.

Existem diferentes tipos de extração/recuperação da lignina. Nenhum deles permite obtê-la em sua forma nativa, como no vegetal, pois há interferência entre o procedimento de isolamento químico e a estrutura das ligninas in situ (protolignina) [45]. O processo comercial mais comum é o Kraft, utilizado nas indústrias de polpação, papel e celulose, correspondendo a cerca de $85 \%$ da lignina recuperada no mundo [19]. Existem outros métodos menos utilizados que são eventualmente empregados, tais como explosão a vapor, método organosolv, digestão enzimática, método soda, entre outros. Outro fator que influencia as propriedades da lignina é a sua matéria-prima de origem. Há sensíveis diferenças da lignina extraída da madeira oriunda de folhosas ("hardwood"), da madeira oriunda de coníferas ("softwood") ou da gramínea. Isso porque a lignina pode ser composta por três subunidades essenciais: a guaiacil, a p-hidroxifenil e a siringil. Dependendo da sua origem, essas unidades se encontram em diferentes proporções no vegetal, facultando propriedades distintas no processo de extrusão. Uma lignina essencialmente guaiacil (mais que $90 \%$ de unidades de guaiacil), com presença de unidades p-hidroxifenil, tem maior dificuldade de extrusão, embora seja mais viável para termoestabilizar. Em contrapartida, a lignina com proporções distintas de guaiacil e siringil extrudam mais facilmente e têm dificuldade em formar ligações cruzadas [8] . Essa diferença de comportamento térmico entre as diferentes estruturas se justifica pela formação de unidades condensadas, mais evidentes em guai- 
acil [46]. Esse fato esclarece o porquê lignina de madeira oriunda de coníferas (lignina guaiacil) é mais difícil para extrudar comparada com madeira oriunda de folhosas (lignina siringil) [11].

\subsection{Parâmetros para extrusão}

Para uso da lignina como precursor da fibra de carbono, é fundamental a remoção de contaminantes presentes junto à sua recuperação. Tais impurezas acarretam em comprometimento das propriedades da fibra, além de desfavorecer a extrusão. Os principais contaminantes que podem estar associados à lignina são grãos de areia, diatomáceas, fibras celulósicas, sais inorgânicos, carboidratos e voláteis [투, $\underline{39}, \underline{47}]$.

Figura 3: Estrutura hipotética da lignina de "softwood" e suas unidades
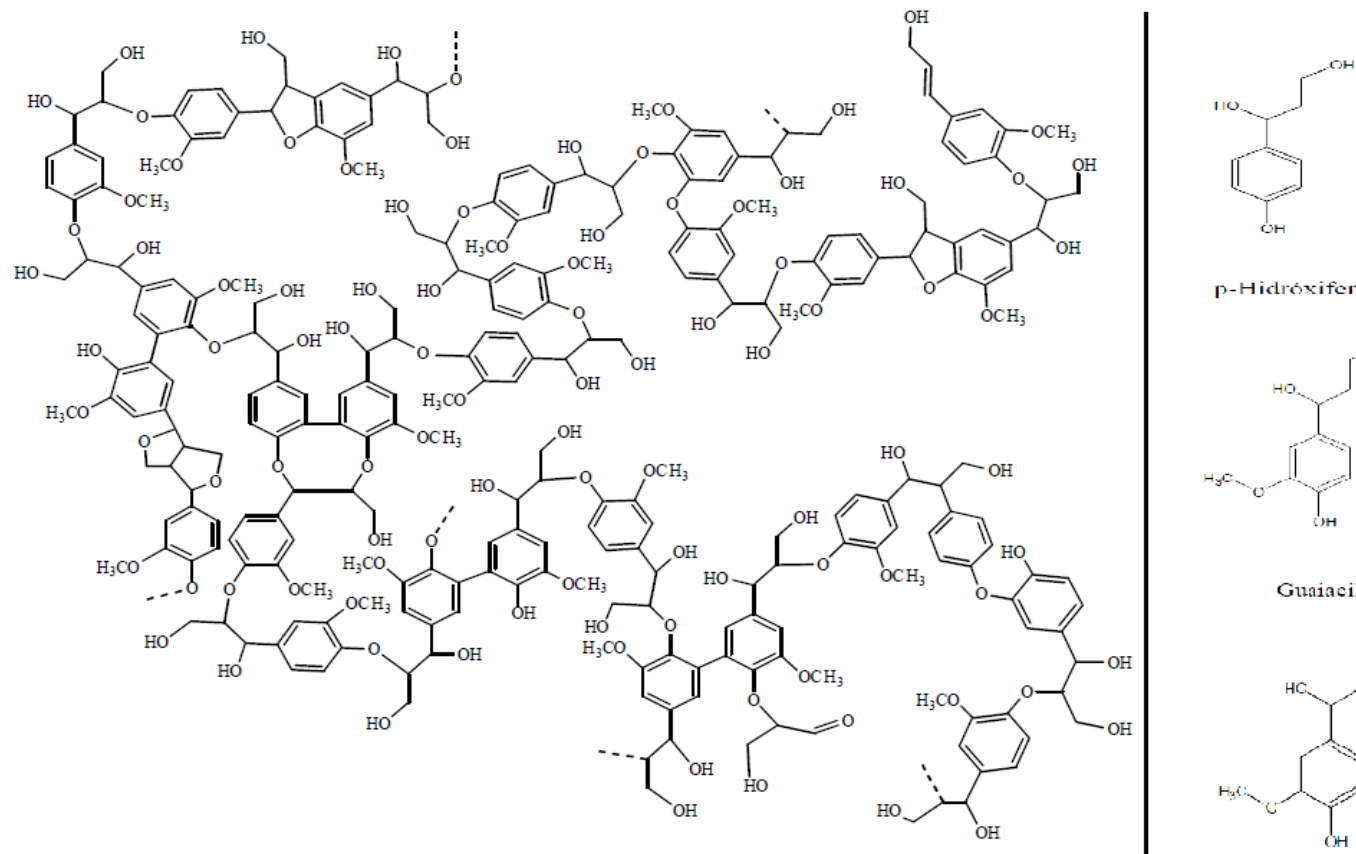

p-Hidroxifenila $(\mathrm{H})$<smiles>COc1cc(C(O)CCO)ccc1O</smiles>

Guaiacila (G)<smiles>CCC1CC(C(C)CCO)=CC(OC)=C1O</smiles>

Siringila (S)

Fonte:[48,49].

A lignina forma um complexo com polissacarídeos. Métodos de hidrólise da ligação da lignina com os polissacarídeos são importantes, pois os carboidratos podem contribuir para a obstrução do orifício da extrusora; o polissacarídeo aumenta o acúmulo de água nas ligações com a lignina e tem baixo rendimento de carbono [16]

Outro fator importante é a polidispersividade, um parâmetro indicativo da homogeneidade da lignina. Polidispersividade alta implica um aumento na temperatura de transição vítrea, o que dificulta a fiação [10]. A eliminação dos possíveis carboidratos presentes favorece a sua redução.

A água adsorvida também precisa ser eliminada, pois, agindo como agente fortemente redutor, carboniza a lignina na etapa de extrusão [50].

A temperatura de fusão ou de amolecimento precisa ser menor que a temperatura de decomposição da lignina. Portanto, é fundamental a determinação dos parâmetros térmicos do polímero, como $\mathrm{T}_{\mathrm{g}}$, temperatura de fusão e temperatura de amolecimento [14]. A temperatura de decomposição da lignina divide a opinião dos autores. Segundo Braun, Holtman e Kadla (2005), ela se encontra em torno de $190{ }^{\circ} \mathrm{C}$, valor em que a homólise da ligação mais fraca (ligação $\beta$-O-4) se inicia. Singh et al. (2005) defendem que de 200-230 ${ }^{\circ} \mathrm{C}$ há degradação dos carboidratos presentes na lignina e que sua degradação mesmo ocorre em $300{ }^{\circ} \mathrm{C}$. Kadla et al. (2002) obtiveram temperaturas de decomposição em torno de $270{ }^{\circ} \mathrm{C}$. Há outros pesquisadores que defendem que a degradação da lignina se dá de 200 a $450{ }^{\circ} \mathrm{C}$, sendo que acima de $400{ }^{\circ} \mathrm{C}$ há pirólise da lignina, reações de decomposição e condensação dos anéis aromáticos [51]. Há uma pesquisa, que relata que as ligações ariléter têm baixa estabilidade térmica e são predominantes, sendo degradadas em temperaturas abaixo de $310{ }^{\circ} \mathrm{C}$; de $230{ }^{\circ} \mathrm{C}$ a $260{ }^{\circ} \mathrm{C}$ haveria a degradação da ramificação da cadeia propânica; e de $275-350{ }^{\circ} \mathrm{C}$ a clivagem das ligações monoméricas $\beta-\beta$ e C-C [39]. Essa divergência de opiniões é uma questão que precisa ser cuidadosamente observada. 
Segundo o Oak Ridge National Laboratory algumas requisições preliminares são necessárias à lignina, para que se alcance o processo de fiação da fibra. São elas: um grau de pureza superior a $99 \%$; um teor de voláteis menor que $5 \%$ a $250{ }^{\circ} \mathrm{C}$; teor de cinzas menor que $1000 \mathrm{ppm}$; e particulados não fusíveis menor que 500 ppm [50].

\subsection{Viabilidade econômica}

Segundo a estimativa do Oak Ridge National Laboratory (ORNL), a pesquisa do uso da lignina como precursor da fibra de carbono tem apontado a matéria-prima como recurso mais barato para o custo do processo, seja por precursor, equipamentos ou operação. Uma comparação estimativa prevê um custo de 21,7 US $\$ / \mathrm{kg}$ para fibra obtida pela PAN e 6,2 US\$/kg para fibra oriunda da lignina [40].

\section{FIBRA DE CARBONO A PARTIR DE LIGNINA}

A lignina tem sido estudada como precursor para obtenção da fibra de carbono, a fim de encontrar um substituto mais barato e menos tóxico que a PAN, oferecendo propriedades mecânicas aplicáveis a interesses industriais e comerciais. Além disso, a lignina está disponível em grande quantidade, pode ser isolada e obtida a preços relativamente competitivos em relação a PAN. Alguns estudos empregaram etapas de modificação estrutural da lignina, outros empregaram aditivos plastificantes, todos como etapas de aprimoramento para fiação e aquisição de um produto final em condições de interesse. Segundo Eckert e Abdullah (2008), isso se deve ao fato da lignina possuir muitas ligações cruzadas, dificultando a sua mudança de fase. Sudo e Shimizu (1992) justificam o fato afirmando que a lignina não possui fusibilidade por ser formada basicamente por ligações desordenadas de carbono-carbono e alquil-aril éter que impedem a rotação das moléculas.

Historicamente, a primeira patente registrada usando a lignina como matéria-prima da fibra de carbono, foi por Otani et al, em nome da Nippon Kayaku Kabushiki Kaisha [52]. A patente descreve um processo utilizando lignina alcalina, tiolignina e lignosulfonatos, extrudados pelos métodos de fiação por fusão, fiação seca e fiação úmida. Uma das propostas desenvolvidas pela invenção foi produzir fibras de carbono com alta ativação utilizando produtos químicos, apenas gases, ou uma mistura dos dois. Dentre os ensaios promovidos utilizou-se lignina adicionada com álcool polivinílico ou à poliacrilonitrila, gerando fibras com uma resistência à tração de $490 \mathrm{MPa}$.

Uma vez que propriedades melhores são necessárias, muitas pesquisas têm sido feitas desde então, em busca de condições que forneçam uma fibra de melhor qualidade.

\subsection{Lignina a partir do processo organosolv}

O processo organosolv utiliza diversos solventes orgânicos para a remoção da lignina, sendo os comumente utilizados o etanol, o metanol e o ácido acético.

Kubo e colaboradores (1998) trabalharam com lignina de lascas de "hardwood" (HW) e "softwood" (SW), obtidas por extração com ácido acético adicionado a um ácido mineral. Foi utilizada uma extrusora com um diâmetro de $0,3 \mathrm{~mm}$, a uma velocidade de $140 \mathrm{~m} \cdot \mathrm{min}^{-1}$. As ligninas de $\mathrm{SW}$ obtidas em ácido acético tiveram os voláteis e as frações infusíveis removidos. As ligninas de HW não necessitaram de tratamento. A temperatura de fiação da fibra obtida pela lignina de SW estava na faixa de $350-370{ }^{\circ} \mathrm{C}$, enquanto a de $\mathrm{HW}$ foi $210{ }^{\circ} \mathrm{C}$. A termoestabilização, quando efetuada, foi promovida em ar, a uma taxa de aquecimento de $30^{\circ} \mathrm{C} \cdot \mathrm{h}^{-1}$ até $250^{\circ} \mathrm{C}$, sendo mantida nessa temperatura por $1 \mathrm{~h}$. A carbonização foi feita em atmosfera de nitrogênio, com uma taxa de aquecimento de $180{ }^{\circ} \mathrm{C} \cdot \mathrm{h}^{-1}$ até a temperatura de $1000^{\circ} \mathrm{C}$. A fibra verde de lignina oriunda de "hardwood" (HAL) quando diretamente carbonizada, fundiu e grudaram umas nas outras, precisando ser previamente termoestabilizada. Já as fibras verdes de lignina de "softwood" (SAL) puderam ser carbonizadas diretamente. Experimentou-se termoestabilizá-las antes, percebendo uma considerável diminuição de poros com o tratamento. Os resultados das propriedades mecânicas das fibras obtidas encontram-se registrados na Tabela 3.

Kadla et al. (2002) trabalharam com lignina extraída pelo processo Alcell, Repap. Trata-se de um processo autocatalítico ácido, sem aditivos, que utiliza etanol/água como solvente [53]. Obteve-se fiação a uma temperatura na faixa de $138-165^{\circ} \mathrm{C}$, a uma velocidade de $74 \mathrm{~m} \cdot \mathrm{min}^{-1}$, usando um equipamento Atlas Laboratory Mixing Extruder com 1/32 polegadas de diâmetro. A termoestabilização das fibras foi promovida em ar, a uma taxa de aquecimento de $12{ }^{\circ} \mathrm{C} \cdot \mathrm{h}^{-1}$ até atingir $250{ }^{\circ} \mathrm{C}$. Manteve-se a temperatura por $1 \mathrm{~h}$. A carbonização foi feita em atmosfera de nitrogênio, a uma taxa de aquecimento de $180^{\circ} \mathrm{C} \cdot \mathrm{h}^{-1}$ até atingir $1000{ }^{\circ} \mathrm{C}$. Os experimentos utilizaram a lignina pura e com a adição de óxido de polietileno (PEO) em diferentes proporções. Concluiu-se que havia uma redução na temperatura de extrusão até uma inclusão de $25 \%$ de PEO, enquanto proporções mais altas desfavoreciam a mesma. As fibras com a adição de PEO não puderam ser termoestabilizadas já que fundiram, tendo-se então de carbonizá-las diretamente. Porém, isso provocou a sua 
fusão. Apenas obtiveram-se resultados com a lignina pura. Os valores das propriedades mecânicas podem ser encontrados na Tabela 3.

Lin et al. (2012) utilizaram a lignina-PEG, produto do processo de solvólise de lascas de "softwood" de cedro, usando polietileno glicol (PEG) na presença de ácido sulfúrico como catalisador. A fibra foi obtida usando um equipamento com um único orifício de diâmetro $0,8 \mathrm{~mm}$. A temperatura de obtenção do fio variou na faixa de $145-172{ }^{\circ} \mathrm{C}$, com velocidade de operação variando entre $45-67 \mathrm{~m} \cdot \mathrm{min}^{-1}$ usando o nitrogênio pressurizado. A termoestabilização foi conduzida em ar ou oxigênio, até a temperatura atingir $250{ }^{\circ} \mathrm{C}$, com taxas de aquecimento variando de $0,1 \mathrm{a} 0,5^{\circ} \mathrm{C} \cdot \mathrm{min}^{-1}$. Essa temperatura foi mantida por $1 \mathrm{~h}$. Inesperadamente, todas as fibras submetidas às diferentes taxas de aquecimento fundiram e aderiram umas às outras. Com a inviabilidade de usar taxas de aquecimento menores, um processo de pré-tratamento químico foi efetuado. As condições ótimas foram encontradas imergindo as fibras em solução de $\mathrm{HCl}$ na concentração de 6 mol.L $\mathrm{L}^{-1}$. As fibras estabilizadas quimicamente foram lavadas duas vezes com água destilada e secas em forno a $105^{\circ} \mathrm{C}$ por $2 \mathrm{~h}$. As fibras foram então submetidas à termoestabilização na taxa de $0,5^{\circ} \mathrm{C} \cdot \mathrm{min}^{-1}$. A etapa de carbonização foi conduzida com uma taxa de aquecimento de $3{ }^{\circ} \mathrm{C} \cdot \mathrm{min}^{-1}$ até $1000{ }^{\circ} \mathrm{C}$ sob atmosfera de nitrogênio. As fibras obtidas apresentaram algumas rachaduras na superfície axial e poros ao longo da superfície radial. As propriedades mecânicas obtidas encontram-se registradas na Tabela 3, em que CF-2h, CF-4h, CF-6h correspondem respectivamente ao tempo de 2, 4 e 6 h de exposição da fibra de carbono à solução de $\mathrm{HCl}$.

Tabela 3: Propriedades Mecânicas das Fibras

(continua)

\begin{tabular}{|c|c|c|c|c|c|c|}
\hline HAL & $\begin{array}{c}\text { Diâmetro } \\
(\mu \mathrm{m}) \\
26 \pm 2\end{array}$ & $\begin{array}{c}\text { Resistência a } \\
\text { tração }(\mathrm{MPa}) \\
5,8 \pm 1,7\end{array}$ & 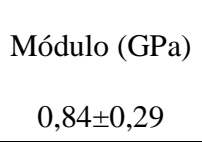 & $\begin{array}{l}\text { Elongação } \\
(\%) \\
0,75 \pm 0,14\end{array}$ & $\begin{array}{c}\text { Rendimento (\%) } \\
32,7\end{array}$ & $\begin{array}{c}\text { Referência } \\
{[\underline{54]}}\end{array}$ \\
\hline SAL & $84 \pm 15$ & $26,4 \pm 3,1$ & $3,59 \pm 0,43$ & $0,71 \pm 0,14$ & 20,3 & [54] \\
\hline Alcell & $31 \pm 3$ & $388 \pm 123$ & $40 \pm 14$ & $1,00 \pm 0,23$ & 40 & [11] \\
\hline HWKL & $46 \pm 8$ & $422 \pm 80$ & $40 \pm 11$ & $1,12 \pm 0,22$ & 45,7 & [11] \\
\hline $\begin{array}{c}\text { HWKL PEO (100 } \\
\text { K) } 97-3^{1}\end{array}$ & $34 \pm 4$ & $448 \pm 70$ & $51 \pm 13$ & $0,92 \pm 021$ & 43,7 & [11] \\
\hline $\begin{array}{l}\text { HWKL PEO (100 } \\
\text { K) } 95-5^{2}\end{array}$ & $46 \pm 3$ & $396 \pm 47$ & $38 \pm 5$ & $1,06 \pm 0,14$ & 45 & [11] \\
\hline $\mathrm{CF}-2 \mathrm{~h}$ & $11,5 \pm 2,0$ & $441 \pm 100$ & $23 \pm 5,4$ & $2,00 \pm 0,5$ & - & [46] \\
\hline CF-4h & $10,4 \pm 1,3$ & $457 \pm 188$ & $26,2 \pm 13,3$ & $2,1 \pm 1,1$ & - & [46] \\
\hline CF-6h & $10,2 \pm 1,2$ & $451 \pm 156$ & $24,7 \pm 7,2$ & $1,6 \pm 0,8$ & - & [46] \\
\hline LK & $49 \pm 1$ & $412 \pm 39$ & $41 \pm 3$ & - & 46 & [55] \\
\hline LA & $47 \pm 2$ & $379 \pm 34$ & $37 \pm 4$ & - & 42 & [55] \\
\hline LP & $49 \pm 2$ & $370 \pm 38$ & $36 \pm 1$ & - & 46 & [55] \\
\hline HHL & $7,6 \pm 2,7$ & $660 \pm 230$ & $40,7 \pm 6,3$ & $1,63 \pm 0,19$ & $15,7-17,4$ & [4] \\
\hline CF-1 & - & 394 & - & 1,22 & 54,8 & [57] \\
\hline CF-2 & - & 311 & - & 1,00 & 54,8 & [57] \\
\hline CF-3 & - & 455 & - & 1,4 & 53,7 & [57] \\
\hline CF-EXL2 & - & 450 & - & 1,2 & 43,7 & [57] \\
\hline Lignina/SPP 95-5 & $47 \pm 5$ & 332 & 57 & 0,89 & - & [1] \\
\hline Lignina/SPP 75-25 & $76 \pm 9$ & 155 & 29 & 0,59 & - & [18] \\
\hline Lignina/PET 95-5 & $31 \pm 5$ & 669 & 84 & 1,10 & - & {$[\underline{18}]$} \\
\hline Lignina/PET 75-25 & $34 \pm 5$ & 703 & 94 & 1,06 & - & {$[\underline{18}]$} \\
\hline
\end{tabular}

\footnotetext{
${ }^{1}$ 97-3 são as proporções de lignina e PEO, respectivamente.

2 95-5 são as proporções de lignina e PEO, respectivamente.
} 
(conclusão)

\begin{tabular}{c|c|c|c|c|c|c}
\hline & $\begin{array}{c}\text { Diâmetro } \\
(\mu \mathrm{m})\end{array}$ & $\begin{array}{c}\text { Resistência a } \\
\text { tração }(\mathrm{MPa})\end{array}$ & Módulo (GPa) & $\begin{array}{c}\text { Elongação } \\
(\%)\end{array}$ & Rendimento $(\%)$ & Referência \\
\hline${\text { Fibra } 1^{3}}$ & - & $2,32(\mathrm{gf} / \mathrm{den})$ & $23,55(\mathrm{gf} / \mathrm{den})$ & 12,4 & - & {$[\underline{12}]$} \\
\hline Fibra 2 & - & $2,43(\mathrm{gf} / \mathrm{den})$ & $22,72(\mathrm{gf} / \mathrm{den})$ & 11 & - & {$[\underline{12}]$} \\
\hline Fibra 3 & - & $2,73(\mathrm{gf} / \mathrm{den})$ & $19,53(\mathrm{gf} / \mathrm{den})$ & 13,10 & - & {$[\underline{12}]$} \\
\hline Fibra A & $94,5 \pm 16,4$ & $58,3 \pm 35,2$ & $4,4 \pm 1,77$ & $1,57 \pm 1,08$ & - & {$[\underline{10}]$} \\
\hline Fibra B & $103 \pm 3,5$ & $150 \pm 20$ & $49,1 \pm 14,4$ & $0,31 \pm 0,11$ & - & {$[\underline{10}]$} \\
\hline PAN comercial & $6-8$ & 380 & 228 & 1,6 & - & {$[\underline{21}]$} \\
\hline $\begin{array}{c}\text { Piche mesofási- } \\
\text { co }^{7}\end{array}$ & 11 & $1380-3100$ & $170-241$ & 0,9 & - & {$[\underline{21}]$} \\
\hline
\end{tabular}

Fonte: Souto,F.; Calado,V.; Pereira Jr., N.

\subsection{Lignina pirolítica}

A pirólise rápida da biomassa, um processo de desperdício zero, gera três produtos: gás de síntese, bio-óleo e carvão sólido. A instabilidade do bio-óleo como combustível deve-se à lignina pirolítica presente, representando cerca de $20 \%$ em massa do material. Qin e Kadla isolaram a lignina pirolítica do bio-óleo de serragem de "hardwood" proveniente da Dynamotive Energy Systems Corp. Os autores trabalharam ainda com lignina Alcell da Repap Enterprises e lignina Kraft da MeadWestvaco Corp [54]. Como a lignina pirolítica (LP) tem menor massa molar, ela forneceu um extrudado a temperaturas mais baixas que as de Alcell e Kraft.

Procedeu-se com um pré-tratamento térmico antes da extrusão, para remoção de voláteis de baixa massa molar. As ligninas Kraft (LK) e Alcell (LA) foram pré-tratadas a $160{ }^{\circ} \mathrm{C}$ por 30 min, a cerca de 30 $\mathrm{KPa}$, enquanto a LP manteve as mesmas condições por $1 \mathrm{~h}$. A termoestabilização foi conduzida em ar, a uma taxa de aquecimento de $0,5^{\circ} \mathrm{C} \cdot \mathrm{min}^{-1}$ até $250{ }^{\circ} \mathrm{C}$ e mantida a essa temperatura por $1 \mathrm{~h}$. Foi aplicada uma tensão na fibra durante a etapa. A taxa de aquecimento na carbonização foi de $3^{\circ} \mathrm{C} \cdot \mathrm{min}^{-1}$ até $1000^{\circ} \mathrm{C}$, sem tensão. As propriedades mecânicas das fibras obtidas pelos autores encontram-se na Tabela 3.

\subsection{Lignina de explosão a vapor}

A lignina de "hardwood" foi removida com metanol por explosão a vapor por Sudo e Shimizu, na temperatura de $203{ }^{\circ} \mathrm{C}$ (pressão de vapor: $16 \mathrm{~kg} \cdot \mathrm{cm}^{-2}$ ) por $10 \mathrm{~min}$ [4].

Depois de lavada e seca, $30 \mathrm{~g}$ de lignina foram hidrogenadas com catalisador de Raney-Ni em solução aquosa de $\mathrm{NaOH} 2 \%$, a $250{ }^{\circ} \mathrm{C}$, por $1 \mathrm{~h}$. A lignina sem hidrogenação extrudou por um orifício de $0,3 \mathrm{~mm}$, em atmosfera de nitrogênio, com pressão de $10 \mathrm{kgf} \cdot \mathrm{cm}^{-2}$, a uma temperatura de $101{ }^{\circ} \mathrm{C}$. O fio obtido foi muito quebradiço. A lignina hidrogenada e tratada (HL) foi fiada em $70{ }^{\circ} \mathrm{C}$, fornecendo uma fibra flexível, porém difícil de bobinar. Para resolver a questão, a HL foi submetida a um tratamento térmico nas temperaturas de 300,330 e $340{ }^{\circ} \mathrm{C}$ por 30 min em atmosfera de nitrogênio ou vácuo (HHL). Essas ligninas (HHL) foram fiadas continuamente em uma faixa de temperatura de $155-180{ }^{\circ} \mathrm{C}$, com velocidade de $100 \mathrm{~m} \cdot \mathrm{min}^{-1}$. Os fios obtidos foram chamados de fibras verdes. Essas fibras verdes de HHL foram submetidas a uma termoestabilização em ar, com uma taxa de aquecimento de $1-2{ }^{\circ} \mathrm{C} \cdot \mathrm{min}^{-1}$, até $210^{\circ} \mathrm{C}$. A carbonização foi feita a uma taxa de $5{ }^{\circ} \mathrm{C} \cdot \mathrm{min}^{-1}$, até a temperatura de $1000{ }^{\circ} \mathrm{C}$, em atmosfera de nitrogênio, mantendo-se assim por 20 minutos. Os dados das propriedades mecânicas da fibra final obtida encontram-se registrados na Tabela 3.

Os mesmos autores e seus colaboradores trabalharam com duas extrações: usaram o processo anterior de extração (EXL-1) [4] e um novo (EXL-2) [55]. A lignina do processo EXL-2 foi extraída com 1\% de Na$\mathrm{OH}$, por explosão a vapor a $20 \mathrm{kgf} \cdot \mathrm{cm}^{-2}$, a $215^{\circ} \mathrm{C}$ por $6 \mathrm{~min}$.

\footnotetext{
${ }^{3}$ Proporção de acrilonitrila - lignina de 5:5

${ }^{4}$ Proporção de acrilonitrila - lignina de 7:3

${ }^{5}$ Proporção de acrilonitrila - lignina de 8:2

${ }^{6}$ Fibra de carbono comercial de PAN de módulo padrão da Zoltek

${ }^{7}$ Fibra de carbono comercial de baixo módulo da Zoltek
} 
A EXL-1 foi submetida à fenolização na faixa de $180-300{ }^{\circ} \mathrm{C}$ por $2-5$ h. Após alguns ensaios, com diferentes temperaturas e tempos de reação, obteve-se melhor resultado de fenolização a $250{ }^{\circ} \mathrm{C}$ por $3 \mathrm{~h}$. A lignina fenolizada teve excelente fusão quando pré-tratada a $280{ }^{\circ} \mathrm{C}$ por $40 \mathrm{~min}$, em pressão reduzida. Esse material forneceu uma fibra verde, que foi termoestabilizada a $300{ }^{\circ} \mathrm{C}$, com uma taxa de aquecimento de $60{ }^{\circ} \mathrm{C} \cdot \mathrm{h}^{-1}$, em ar. A carbonização foi conduzida em atmosfera de nitrogênio, de duas maneiras distintas. A primeira (CF-1) foi feita a uma taxa de aquecimento de $5{ }^{\circ} \mathrm{C} \cdot \mathrm{min}^{-1}$ até atingir $1000^{\circ} \mathrm{C}$. A segunda (CF-2) foi aquecida a uma taxa de $10{ }^{\circ} \mathrm{C} \cdot \mathrm{min}^{-1}$ até $300^{\circ} \mathrm{C}$ e mantida por $10 \mathrm{~min}$; depois, a uma taxa de $0,5^{\circ} \mathrm{C} \cdot \mathrm{min}^{-1}$ até $450{ }^{\circ} \mathrm{C}$, mantida por $10 \mathrm{~min}$; e finalmente, a uma taxa de $10{ }^{\circ} \mathrm{C} \cdot \mathrm{min}^{-1}$, até $1000{ }^{\circ} \mathrm{C}$. Não foram evidenciadas variações significativas nas propriedades de ambas.

Outro experimento tentado com a EXL-1 foi a fenolização usando creosoto, na mesma proporção em massa da lignina, a $300{ }^{\circ} \mathrm{C}$ por $1 \mathrm{~h}$. A lignina fenolizada, depois de filtrada a vácuo e seca, foi pré-tratada termicamente a $250{ }^{\circ} \mathrm{C}$ por $60 \mathrm{~min}$, a vácuo. A extrusão procedeu com sucesso, a uma velocidade de 300 $\mathrm{m} \cdot \mathrm{min}^{-1}$. A fibra verde obtida foi termoestabilizada em ar, a $300{ }^{\circ} \mathrm{C}$, com taxa de aquecimento de $60{ }^{\circ} \mathrm{C} \cdot \mathrm{h}^{-1}$. A etapa de carbonização foi feita na taxa de $5{ }^{\circ} \mathrm{C} \cdot \mathrm{min}^{-1}$, até a temperatura atingir $1000{ }^{\circ} \mathrm{C}(\mathrm{CF}-3)$. Os resultados das propriedades mecânicas, quando comparados em relação à lignina hidrogenada e às fenolizadas, apresentaram valores similares, indicando que o creosoto pode ser usado eficazmente como agente de fenolização, sendo um reagente mais barato.

A lignina de EXL-2 foi fenolizada em diferentes proporções de solução de fenol e água, com e sem adição de ácido acético como catalisador. Os experimentos não evidenciaram variações significativas no rendimento e no ponto de amolecimento da lignina com a adição do catalisador. Os autores reportaram algumas proporções adequadas, em que obtiveram resultados satisfatórios. Quando esses produtos foram pré-tratados termicamente a $220{ }^{\circ} \mathrm{C}$ por $20 \mathrm{~min}$, pode-se acompanhar a obtenção da fibra verde que foi imediatamente termoestabilizada e carbonizada (CF-EXL2), como descrito anteriormente. Os resultados das propriedades mecânicas encontram-se na Tabela 3. Os processos inclusive foram patenteados pelos autores [ㅌ6].

\subsection{Lignina acetilada}

Eckert e Abdullah (2008) patentearam um processo de obtenção da fibra de carbono utilizando lignina modificada estruturalmente. O processo de modificação empregado foi a acetilação da lignina. A invenção utiliza lignina de "softwood" oriunda do processo Kraft (SWKL).

Foram testados alguns ensaios de acetilação da lignina com e sem catalisador. A lignina foi acetilada usando uma mistura de anidrido acético e piridina como catalisador. A lignina acetilada foi pré-tratada termicamente a $140{ }^{\circ} \mathrm{C}$ a vácuo por $1 \mathrm{~h}$, para remoção de voláteis. $\mathrm{O}$ material foi extrudado a $220{ }^{\circ} \mathrm{C}$, usando uma taxa de aquecimento de $1,7^{\circ} \mathrm{C} \cdot \mathrm{s}^{-1}$. A termoestabilização se deu em ar, a $240{ }^{\circ} \mathrm{C}$, com taxa de aquecimento de $0,2{ }^{\circ} \mathrm{C} \cdot \mathrm{min}^{-1}$, mantendo-se a temperatura final por $2 \mathrm{~h}$. A carbonização foi feita em atmosfera de nitrogênio, com uma taxa de aquecimento de $4{ }^{\circ} \mathrm{C} \cdot \mathrm{min}^{-1}$ até $1150{ }^{\circ} \mathrm{C}$, sendo mantida a temperatura por $2 \mathrm{~h}$.

A patente não apresenta os dados de propriedades mecânicas do material obtido, fornecendo apenas micrografias das fibras geradas.

\subsection{Lignina com aditivos}

Em seu artigo, Kadla, Kubo, et al (2002) comparam a lignina Alcell, com e sem PEO, com lignina Kraft, com e sem PEO.

A lignina Alcell foi abordada no item 6.1 desta revisão. Foram usadas ligninas do processo Kraft de "softwood" (SWKL) e de "hardwood" (HWKL). Foram estudadas as ligninas puras e misturadas com PEO com diferentes proporções. Todas foram pré-tratadas termicamente.

A SWKL não fundiu quando submetida à faixa de $140-200{ }^{\circ} \mathrm{C}$, tendo carbonizado. A HWKL fundiu na faixa de $195-228{ }^{\circ} \mathrm{C}$ fornecendo boa extrusão. Com a adição de PEO, pode-se observar que houve um favorecimento da temperatura de extrusão. A fibra verde de lignina pura foi termoestabilizada em ar, com taxa de aquecimento de $120^{\circ} \mathrm{C} \cdot \mathrm{h}^{-1}$ até $250{ }^{\circ} \mathrm{C}$, sendo mantida por $1 \mathrm{~h}$ na temperatura final. A fibra verde de lignina misturada com PEO só pode ser termoestabilizada com proporções inferiores a $5 \%$ de PEO (100K PEO) e inferiores a $12,5 \%$ de PEO (600K PEO), nas mesmas condições citadas. Depois de carbonizadas a uma taxa de $180{ }^{\circ} \mathrm{C} \cdot \mathrm{h}^{-1}$ até $1000{ }^{\circ} \mathrm{C}$ em nitrogênio, obtiveram-se fibras sem microporos, cujas propriedades mecânicas encontram-se na Tabela 3.

Kubo e Kadla (2005) estudaram a lignina de "hardwood" do processo Kraft, misturada com politereftalato de etileno (PET) e polipropileno (PP). Utilizaram-se PP isotático Mw= $580000(\mathrm{HPP})$, PP isotático Mw $=190000$ (MPP), PP isotático Mw = 12000 (LPP) e PP sindiotático Mw = 127000 (SPP). Os procedimentos padrões de lavagem e desvolatilização da lignina foram empregados. Diferentes proporções de lignina e PET ou lignina e PP foram testadas, fornecendo fibras contínuas para os diferentes casos e temperaturas. As propriedades mecânicas das fibras obtidas pelos autores encontram-se registradas na Tabela 3. 
Marandur, Kim, et al (2012) obtiveram fibra de carbono usando poliacrilonitrila com um copolímero de lignina de "hardwood". Após a oligomerização/polimerização da acrilonitrila, procedeu-se uma reação de copolimerização com a lignina, com condições e reagentes específicos. Foi utilizado processo de fiação úmida, com $16 \%$ em massa do copolímero de PAN-lignina, usando dimetilsulfóxido (DMSO) como solvente. As fibras foram bombeadas para o banho de coagulação (100\% água), por 150 orifícios de 0,05 mm de diâmetro. A temperatura de extrusão foi de $150{ }^{\circ} \mathrm{C}$, com uma velocidade de 6 a $8 \mathrm{~m} \cdot \mathrm{min}^{-1}$. A termoestabilização foi feita em duas etapas e sob ação de uma tensão de 7,86 Pa, usando uma taxa de aquecimento de $1^{\circ} \mathrm{C} \cdot \mathrm{min}^{-1}$ até a temperatura de $105{ }^{\circ} \mathrm{C}$, em ar, mantendo a isoterma por $1 \mathrm{~h}$ e após, elevou-se a temperatura a $280{ }^{\circ} \mathrm{C}$, em atmosfera de nitrogênio, mantendo por $1 \mathrm{~h}$. A carbonização procedeu em nitrogênio, a uma taxa de aquecimento de $5^{\circ} \mathrm{C} \cdot \mathrm{min}^{-1}$, até $800{ }^{\circ} \mathrm{C}$. Os valores para as propriedades mecânicas estão registrados na Tabela 3 .

Schmidt (1992) estudou a lignina de "softwood" do processo Kraft com a adição de $28 \%$ de n-metilpirrolidinona (NMP). $\mathrm{O}$ autor obteve uma fibra contínua a $130{ }^{\circ} \mathrm{C}$, extrudando a uma velocidade de 100 $\mathrm{m} \cdot \mathrm{min}^{-1}$. Nenhuma etapa de termoestabilização foi promovida. A carbonização foi feita de duas formas distintas, ambas em atmosfera de argônio. A corrida A usou uma taxa de aquecimento de $5{ }^{\circ} \mathrm{C} \cdot \mathrm{min}^{-1}$, com um perfil de temperatura de 90 a $800{ }^{\circ} \mathrm{C}$, mantendo uma isoterma por $1 \mathrm{~h}$. A corrida B teve um perfil de 90 a 250 ${ }^{\circ} \mathrm{C}$, uma taxa de $10{ }^{\circ} \mathrm{C} \cdot \mathrm{min}^{-1} \mathrm{com}$ isoterma de $15 \mathrm{~min}$, depois um perfil de $250-1000{ }^{\circ} \mathrm{C}$ a uma taxa de 5 ${ }^{\circ} \mathrm{C} \cdot \mathrm{min}^{-1}$ com isoterma de $1 \mathrm{~h}$. A Tabela 3 contém as propriedades obtidas com as fibras.

\subsection{Lignina do licor verde}

Luo (2010) trabalhou com licor verde com diferentes extrações (0-6\%) de hemicelulose e isolou a lignina por hidrólise. Obteve uma fibra contínua com todas as proporções de extração, porém com temperaturas distintas de extrusão. Conduziu a etapa de termoestabilização em ar, com taxa de aquecimento de $1^{\circ} \mathrm{C} \cdot \mathrm{min}^{-1}$ até atingir $105{ }^{\circ} \mathrm{C}$ mantendo essa temperatura por $1 \mathrm{~h}$. Após esse tempo, aplicou uma taxa de aquecimento de $0,25^{\circ} \mathrm{C} \cdot \mathrm{min}^{-1}$ até $200{ }^{\circ} \mathrm{C}$, mantendo a isoterma por $24 \mathrm{~h}$. A carbonização foi feita em atmosfera de argônio, com taxa de aquecimento de $5{ }^{\circ} \mathrm{C} \cdot \mathrm{min}^{-1}$ até $1000{ }^{\circ} \mathrm{C}$. As fibras encolheram durante a etapa de termoestabilização e reproduziram fibras de carbono muito quebradiças, com propriedades mecânicas fracas. Foram evidenciadas muitas imperfeições reportadas nas micrografias ao longo do trabalho. Os dados das propriedades mecânicas não foram fornecidos.

\section{CONCLUSÕES}

A lignina tem sido amplamente estudada como potencial precursor para a obtenção da fibra de carbono. Ainda que as propriedades obtidas com as mesmas sejam inferiores às de PAN, há diversas áreas de aplicações em diversos setores que poderiam incentivar a sua produção.

Alguns parâmetros ainda precisam ser estudados e muitas pesquisas precisam ser feitas, até porque as propriedades da lignina variam em função de muitas variáveis, desde a sua matéria-prima até o seu processo de recuperação. A experiência tem mostrado que a remoção de sais, particulados, carboidratos e voláteis exerce papel fundamental no processo. O pré-tratamento térmico anterior à extrusão também tem demonstrado contribuir favoravelmente ao processo. Embora ele aumente a massa molar, provavelmente por reações de condensação entre unidades fenólicas, remoção de voláteis, água e componentes de baixa massa molar são necessários. O inconveniente é que o aumento da massa molar aumenta a temperatura de transição vítrea, tornando a temperatura de extrusão mais elevada.

Embora a lignina sofra auto-oxidação em decorrência de sua estrutura, a termoestabilização tem se apresentado como uma etapa indispensável ao processo.

Para efeitos de comparação, seria imprescindível uma padronização dos diâmetros das fibras. Diâmetros elevados têm maior probabilidade de produzir fibras com poros e defeitos estruturais. Além disso, o aumento do diâmetro diminui a resistência à tração. A fibra comercial de PAN tem um diâmetro médio de 7 $11 \mu \mathrm{m}$, devendo servir como parâmetro de referência.

A pesquisa tem futuro promissor, desvinculando do petróleo a produção de fibras de carbono, barateando assim custos e aproveitando rejeitos industriais, transformando-os em produtos de alto valor agregado com amplo campo de aplicações. Essa proposta vai ao encontro do conceito de biorrefinaria, que está em pleno desenvolvimento em suas pesquisas e aplicações no contexto global. Sua integração alicerça e impulsiona o projeto fornecendo apoio em suas diretrizes e disponibilizando a matéria-prima para sua execução. 


\section{BIBLIOGRAFIA}

[1] HEGDE, R. R., DAHIYA, A., KAMATH, M. G. Carbon Fiber, 2004. Disponivel em: <http://web.utk.edu/ mse/Textiles/CARBON\%20FIBERS.htm>. Acesso em: 30 novembro 2013.

[2] HUANG, X. "Fabrication and Properties of Carbon Fibers", Materials, v. 2, pp. 2369-2403, 2009.

[3] CALLISTER, W. D. "Material Science and engineering", Nova Iorque, John Willey e Sons. Inc, 1999.

[4] SUDO, K., SHIMIZU, K. A new carbon fiber from lignin, Journal of applied polymer science, v. 44, pp. 127-134, Jan 1992.

[5] LUO, J. Lignin-based carbon fiber, Dissertação de mestrado, Universidade de Maine, [s.l.], 2010.

[6] WAZIR, A. H., KAKAKHEL, L. "Preparation and characterization of pitch-based carbon fibers", New carbon materials, v. 24, n. 1, pp. 83-88, 2009.

[7] ZOLTEK. Zoltek, commercial carbon fiber. What is carbon fiber. Disponivel em: <http://www.zoltek.com/carbonfiber/>. Acesso em: 30 novembro 2013.

[8] BAKER, F. S. Frontiers in biorefining: biobased products from renewable carbon. Utilization of sustainable resources for production of carbon fiber materials for structural and energy efficiency applications., 2010. Disponivel em: <http://www.frontiersinbiorefining.org/2010/Resources/fibBaker,\%20Fred.pdf >. Acesso em: 30 novembro 2013.

[9] FORREST, A. et al. Low-cost carbon fiber. Disponivel em: <http://virtual.clemson.edu/caah/synergy/ISSUE-1LCCF.htm〉. Acesso em: 2013 novembro 2013.

[10] SCHMIDL, G. W. Molecular weight and rheology of lignin for carbon fiber, Gainesville, Universidade da Flórida, 1992.

[11] KADLA, J. F. et al. "Lignin-based carbon fibers for composite fiber applications", Carbon, v. 40, pp. 2913-2920, 2002.

[12] MARADUR, S. P. et al. "Preparation of carbon fibers from a lignin copolymer with polyacrylonitrile". Synthetic Metals, v. 162, p. 453-459, 2012.

[13] WARREN, C. D., Low cost carbon fiber overview. Field Technical Manager Transportation Materials Research - Oak Ridge National Laboratory, 2010. Disponivel em: <http://www1.eere.energy.gov/vehiclesandfuels/pdfs/merit_review_2010/lightweight_materials/lm002_ warren_2010_o.pdf>. Acesso em: 30 novembro 2013.

[14] MANSMANN, M., et al., Process of production of carbon fibers, US 3723609, 27 Março 1973.

[15] XIAOJUN, M. . G. Z. "Preparation of carbon fibers from liquefied wood", Wood Sci Technol, v. 44, pp. $3-11,2010$.

[16] COMPERE, A. L., GRIFFITH, W. L., LEITTEN JR., C. F. Oak Ridge National Laboratory. Improving the fundamental properties of fundamental lignin-based carbon fiber for transportation applications. Disponivel em: 〈http://web.ornl.gov/ webworks/cppr/y2001/pres/120145.pdf〉. Acesso em: 02 dezembro 2013.

[17] BRAUN, J. L., HOLTMAN, K. M., KADLA, J. F. "Lignin-Based carbon fibers: Oxidative thermostabilization of kraft lignin", Carbon, v. 43, pp. 385-394, 2005.

[18] KUBO, S., KADLA, J. F., "Lignin-based Carbon Fibers: Effect of Synthetic Polymer Blending on Fiber Properties", Journal of Polymers and the Environment, v. 13, n. 2, pp. 97-105, 2005.

[19] VISHTAL, A., KRASLAWSKI, A. "Challenges in industrial in industrial applications of technical lignins", Bioresource, v. 6, n. 3, pp. 3547-3568, 2011.

[20] FARSANI, R. E. "Production of Carbon Fibers from Acrylic Fibers", In: International Conference on Chemical, Civil and Environment engineering, Dubai, pp. 310-312, 2012.

[21] WALSH, P. J., Carbon Fibers. [s.1.], ASM International , v. 21, 2011. Handbook.

[22] JYH-MING, T.; LAN, B. C. "Formation of nodulated vapor grown carbon fiber", Carbon, v. 38, pp. 
1917-1923, 2000.

[23] ISHIOKA, M., OKADA, T., MATSUBARA, K., "Formation and Characteristics of vapor grown carbon fibers prepared in Linz-Donawitz converter gas", Carbon, v. 30, n. 7, pp. 975-979, 1992.

[24] TING, J., LAN, B. C. "Formation of nodulated vapor grown carbon fiber", Carbon, v. 38, pp. 1917 1923, 2000.

[25] ISHIOKA, M., OKADA, T., MATSUBARA, K. "Formation of vapor-grown carbon fiber in CO-CO2H2 mixtures, I. Influence of carrier gas composition", Carbon, v. 30, n. 6, pp. 859-863, 1992.

[26] PATTON, R. D., et al., "Vapor grown carbon fiber composites with epoxy in poly(phenylene sulfide) matrices", Composites: Part A, v. 30, pp. 1081-1091, 1999.

[27] YONGZHEN, Y. et al. "Preparation of vapor-grown carbon fiber from deoiled asphalt", Carbon , v. 44, pp. 1661-1664, 2006.

[28] KATO, T., KUSAKABE, K., MOROOKA, S., "Process of formation of vapour-grown carbon fiber by gas-phase", Journal of materials Science letters, v. 11, p. 674-677, 1992.

[29] KATO, T., KUSAKABE, K., MOROOKA, S. "Effect of sulphur on formation of vapour-grown carbon fiber", Journal of materials science letters, v. 13, pp. 374-377, 1994.

[30] ENDOA, M. et al. "Vapor-grown carbon fibers (VGCFs) - Basic properties and their battery applications", Carbon, v. 39, pp. 1287-1297, 2001.

[31] TORAY. "Toray's bussiness strategy for carbon fiber composite materials", Toray - Inovation by chemistry, 2012. Disponivel em: 〈http://www.toray.com/ir/pdf/lib/lib_a136.pdf>. Acesso em: 02 dezembro 2013.

[32] EDIE, D. D. "The effect of processing on the structure and properties of carbon fibers", Carbon, v. 36, n. 4, p. 345-362, 1998.

[33] BRITO JR., C. A. R. et al. "PAN fibers obtained by extrusion process using glycerin as plasticizer", In: Congresso Brasileiro de Carbono, V, Rio de Janeiro, [s.n.]. 2011.

[34] HAYASHI, J. et al. "Rapid stabilization of pitch fiber precursor by multi-step thermal oxidation", Carbon, v. 33, pp. 1567-1571, 1995.

[35] JUNIOR, C. F. L. et al. High-volume, low-cost Precursors for carbon fiber production, SAE Technical Paper, [s.1.], 2002.

[36] PAULASKAS, F. L., et al., "Novel Precursor materials and approaches for producing lower cost carbon fiber for high volume industries", Automotive Applications \& Recycling, Edimburgo, [s.n.], 2009.

[37] DERBYSHIRE, F. et al., "Synthesis of isotropic carbon Fibers and activated carbon fibers from pitch precursors", Fuel, v. 80, pp. 245-356, 2001.

[38] DRBOHLAV, J., STEVENSON, W. T. K. "The oxidative stabilization and carbonization of a synthetic mesophase pitch, part i: the oxidative stabilization process", Carbon, v. 33, pp. 693-711, 1995.

[39] BREBU, M., VASILE, C., "Thermal degradation lignin - A review", Cellulose chemistry and technolo$g y$, v. 44, n. 9, pp. 353-363, 2010.

[40] NORBEG, I. Carbon Fibers from Kraft Lignin, Tese de doutorado, KTH Royal Institute of Technology, Stockholm, 2012.

[41] AHMAD, A., ZHONGREN, Y., YOUQING, F. Low Cost Carbon Fiber Technology Development for Carbon Fiber Composite Applications, The University of Tennessee Space Institute, Tennessee, 2008.

[42] KOKOUVI, A. Pretreatment and Pyrolysis of Rayon-based precursor for carbon fiber, Tese de mestrado, The universtity of Tennessee, Tennessee, 2012.

[43] DRESSELHAUS, M. S. "Future directions in carbon science", Annu. Rev. Mater. Sci., v. 27, p.1-34, 1997.

[44] ABREU, H. D. S., OERTEL, A. D. C. "Estudo químico da lignina de Paullinia rubiginosa", CERN, v. 
5, p. 52-60, 1999.

[45] PILÓ-VELOSO, D. "Isolamento e análise estrutural de ligninas", Química Nova, v. 16, p. 435-448, 1993. ISSN 5.

[46] LIN, J. et al. "Thermostabilized carbon fibers from softwood", Bioresources, v. 7, p. 5634-5646, 2012.

[47] UEMURA, S. Pitch Based Carbon Fiber Production Process and Properties. Disponivel em: <http://www.jst.go.jp/sicp/ws2010_tu/abstract/11-Uemura.pdf>. Acesso em: 04 dezembro 2013.

[48] CRESTINI, C., et al. "Oxidative strategies in lignin chemistry: A new environmental friendly approach for the functionalisation of lignin and cellulosic fibers", Catalysis today, v. 156, pp. 8-22, 2010.

[49] SOUZA, C. S. D. Derivatização química e caracterização de uma lignina do bagaço de cana-de-açúcar, Dissertação de mestrado, Universidade Federal de Uberlândia, Uberlândia, 2006.

[50] GELLERSTEDT, G., SJÖHOLM, E., BRODIN, I. The Wood-Based Biorefinery: A Source of Carbon Fiber?, The Open Agriculture Journal, v. 3, pp. 119-124, 2010.

[51] MARABEZI, K. Estudo sistemático das reações envolvidas na determinação dos teores de lignina e holocelulose em amostras de bagaço e palha de cana-de-açúcar, Dissertação de mestrado, Universidade de São Paulo, São Paulo, 2009.

[52] OTANI, S., KIRYU-SHI; FUKUOKA, Y., Method for producing carbonized lignin fiber, US 3461082, 12 Agosto 1969.

[53] HERNANDEZ, J. A. Lignina organosolv de Eucalyptus dunnii Maiden alternativa para síntese de adesivos de poliuretano para madeira, Tese de doutorado, Universidade Federal do Paraná, [s.1.], 2007.

[54] KUBO, S., URAKI, Y., SANO, Y. "Preparation of carbon fibers from softwood lignin by atmospheric acetic acid pulping", Carbon, v. 36, pp. 1119-1124, 1998.

[55] QIN, W.; KADLA, J. F. "Carbon Fibers Based on Pyrolytic Lignin”, Journal of Applied Polymer Science, v. 126, pp. E203-E212, 2012.

[56] SUDO, K., SHIMIZU, K. Method for manufacturing lignin for carbon fiber spinning, 5344921, setembro 1994.

[57] SUDO, K. et al. "A New Modification Method of Exploded Lignin for the of a Carbon Fiber Precursor", Journal of Applied Polymer Science, v. 48, pp. 1485-1491, 1993. 